\title{
Giftinformasjonen 50 år - forgiftningsbehandling før og nå
}

\author{
Giftinformasjonen fyller 50 år i 2011. I løpet av disse årene har både informasjonsvirksomheten, forgiftnings- \\ mønsteret og forgiftningsbehandlingen endret seg. Godt samarbeid mellom Giftinformasjonen og kliniske \\ miljøer er en forutsetning for at informasjonstjenesten og forgiftningsbehandlingen i Norge skal holde et godt \\ faglig nivå.
}

\author{
Dag Jacobsen \\ Akuttmedisinsk avdeling \\ Medisinsk klinikk \\ Oslo universitetssykehus, Ullevål \\ og \\ Avdeling giftinformasjon \\ Helsedirektoratet \\ Tarjei Rygnestad \\ Institutt for laboratoriemedisin, \\ barne- og kvinnesykdommer \\ Det medisinske fakultet \\ Norges teknisk-naturvitenskapelige universitet , \\ og \\ Avdeling giftinformasjon \\ Helsedirektoratet

\section{Berit Muan} \\ bermua@ous-hf.no \\ Erik Andrew \\ Avdeling giftinformasjon \\ Helsedirektoratet
}

Forgiftninger har vært beskrevet så lenge man har notater fra menneskehetens utvikling. I tidligere tider - som nå - er giftstoffer fra naturen blitt brukt og misbrukt til både drap, avretting og i rituelt øyemed. Senere er fremveksten av kjemisk fremstilte stoffer blitt benyttet i samme hensikt. På 1800-tallet kom de mer moderne misbruksstoffene som opium, morfin og kokain på markedet, først legalt og senere illegalt. Mot slutten av forrige årtusen så man etter hvert utviklingen av stoff- og medikamentmisbruk slik vi kjenner det i dag, og med en økende forekomst av selvpåførte forgiftninger. Som ledd i den industrielle utviklingen omgir vi oss med stadig flere kjemikalier og kjemiske produkter som også kan gi akutte helseskadelige effekter. I takt med økende forekomst av forgiftninger utviklet det seg ulike behandlingstradisjoner. Vi vil her belyse fremveksten av moderne forgiftningsbehandling, som er basert på et samarbeid mellom sykehuset som behandler pasienten og kompetanseenheter som Giftinformasjonen.

\section{Forgiftningsepidemiologi - hovedtrender}

I Norge dør i dag i underkant av 500 personer årlig av forgiftning (1). Tallet har vært ganske stabilt de siste ti årene, men er tre ganger høyere enn i slutten av 1960-årene (2). Økningen skyldes først og fremst større misbruk av narkotiske stoffer og legemidler. Tall fra Norsk pasientregister, som kun er tilgjengelig for de om lag ti siste årene, viser at det i denne perioden har vært en svak økning $i$ antall sykehusinnleggelser med forgiftning som diagnosekode, og at antallet $i$ dag ligger på om lag 12000 per år (1). Også her er det forgiftninger med rusmidler som har økt mest. Derimot legges langt færre barn inn med mistanke om forgiftning enn for 50 år siden. Vi antar dette skyldes godt forebyggende arbeid på ulike nivåer (3).

\section{Giftinformasjonen}

På grunn av manglende kunnskap om de mange nye stoffenes toksisitet vokste det i 1950-årene frem et økende behov for regionale/nasjonale kompetanseenheter hvor man kunne rådføre seg for å kunne behandle forgiftninger. I mange vestlige land startet oppbyggingen av slike giftinformasjonssentraler. I Norge var det farmasøyt Elsa Wickstrøm som i 1961 etablerte Giftkarto-

\section{«En av den jubilerende} organisasjonens viktigste oppgaver er å redusere antallet unødvendige henvendelser til legevakt

og sykehus»

teket på Farmakologisk institutt ved Universitetet i Oslo (4). For å sikre best mulig klinisk profil på enheten allierte hun seg med daværende spesiallege på 7 . avdeling på Ullevål sykehus, Erik Enger, som senere ble klinikksjef og professor i nefrologi. Samarbeidet mellom Giftinformasjonen og spesialleger på Ullevål er holdt $\mathrm{i}$ hevd og videreutviklet for å sikre klinisk kompetanse bak informasjonsvirksomheten.
I starten hadde Giftkartoteket kun åpent $\mathrm{i}$ ordinær arbeidstid. For å bistå med informasjon og rådgivning utenom vanlig arbeidstid, anla man i 1964 en kopi av Giftkartoteket på 7. avdeling Ullevål, hvor vakthavende indremedisiner etter beste evne besvarte henvendelser fra andre sykehus, i tillegg til sitt vanlige vaktarbeid (4). Som ledd $i$ en internasjonal harmonisering skiftet Giftkartoteket navn til Giftinformasjonssentralen i 1980. Etter å ha vært samlokalisert med Farmakologisk institutt ved Universitetet i Oslo, flyttet virksomheten i 1988 ned i statlige lokaler sentralt i Oslo (4). For å bedre samarbeidet med det klinisk-toksikologiske miljøet på Ullevål flyttet man i 1991 Giftinformasjonssentralen til lokaler i Ullevål sykehus. Samtidig økte antall henvendelser kraftig (fig 1), slik at henvendelsene på vakttid ikke lenger lot seg håndtere av leger på Ullevål. Giftinformasjonssentralen fikk derfor økte personellressurser og opprettet i 1993 døgnåpen drift. I dag heter institusjonen Giftinformasjonen, og er en avdeling i Helsedirektoratet. Avdelingen har en stab som til sammen utgjør 24 årsverk, to innehar lederstillinger, to administrative stillinger og 19 toksikologfaglige stillinger (farmasøyter, veterinærer og toksikologer). Tre intensivleger med erfaring fra forgiftningsbehandling er ansatt $i$ deltid og fungerer som kliniske bakvakter døgnet rundt.

\section{Ny behandling - bedre prognose}

Før man fikk moderne intensivbehandling med sikring av frie luftveier og respirasjonsunderstøttende behandling, var det viktig å holde pasientene våkne slik at de kunne puste selv og holde frie luftveier. Til dette brukte man store doser sentralstimulerende medikamenter, ulike typer klyster med blant annet kaffe, og i de mest ekstreme tilfellene det krampefremkallende stoffet stryknin ved overdoser med opium $(5,6)$.

De store fremskrittene i forgiftningsbehandlingen i 1950-årene var sikring av frie luftveier og oksygentilførsel, eventuelt også respiratorbehandling. Sirkulasjonssvikt ble behandlet med intravenøse væsker i stedet for sentralstimulerende medikamenter. Behandlingen ble også sentralisert til spe- 


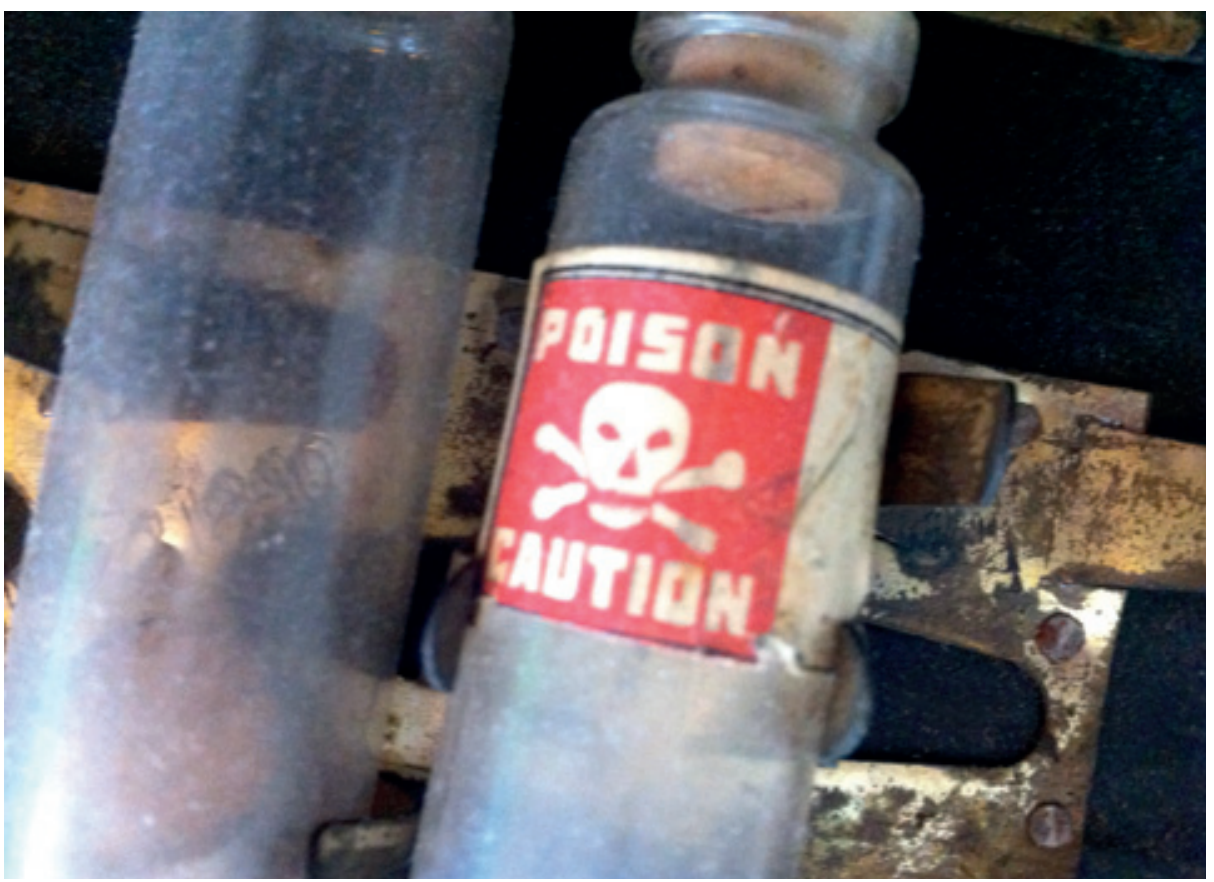

Illustrasjonsfoto E. Dalby

sielle avdelinger som dermed kunne bygge opp spisskompetanse på området (7). Prinsippet var å understøtte kroppens vitale funksjoner og å motvirke komplikasjoner til medikamentet eller giftstoffet var eliminert. Dette prinsippet ble utviklet på Bispebjerg sykehus i København og omtales ofte internasjonalt som The Scandinavian method. Deretter hadde man i 1970-årenet en (feilaktig) optimistisk tro på effekten av så vel dialyse som såkalt hemoperfusjon. Ved hemoperfusjon blir blodet renset gjennom et filter med sterilt aktivt kull, som så skal trekke til seg de fleste medikamenter/toksiner i blodet. Problemet var imidlertid at få hadde forståelse for distribusjonsvolumets betydning for effekten av denne behandlingen. Utover i 1980-årene kom det flere farmakokinetiske studier som klart viste

Totalt antall

henvendelser per år

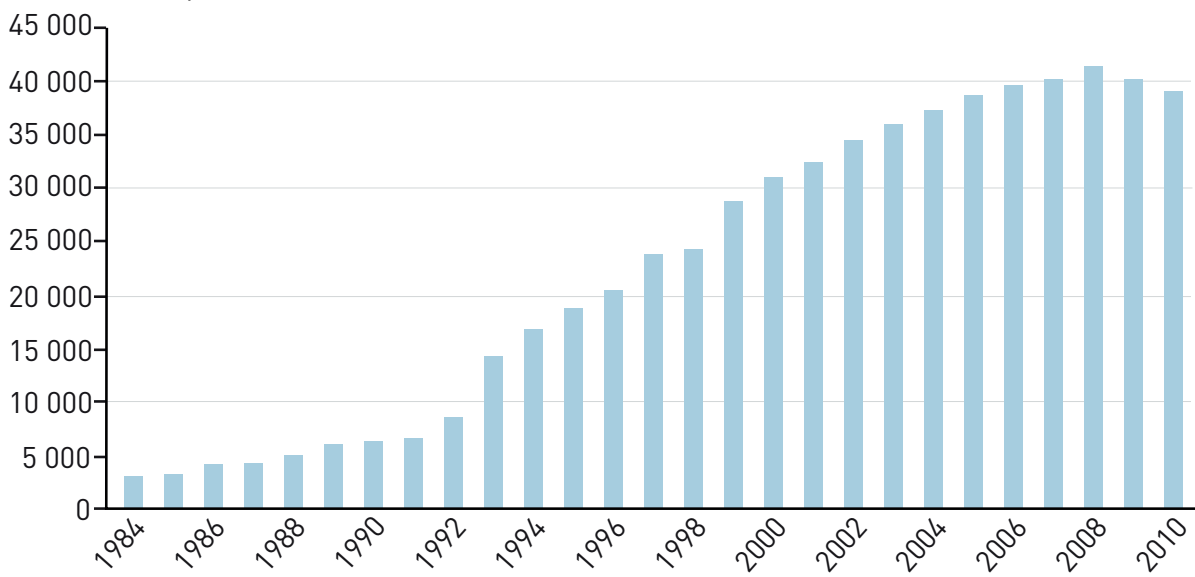

Figur 1 Totalt antall henvendelser per år til Giftinformasjonen i perioden 1984-2010, Tall fra Giftinformasjonens interne årsrapporter for de respektive år noen var direkte farlige (9). En av konklusjonene var også at motgifter må ses på som en gruppe medikamenter med svært forskjellig effektivitet. Det er viktig at den som behandler forgiftningspasienter forstår den begrensede effekten noen motgifter har. Dette vil hjelpe til å holde fokus på støttebehandlingen, som oftest er viktigst.

Anvendelse av dialyse og moderne motgifter de senere årene har forbedret prognosen ved forgiftninger slik at man nå er nede på en akutt mortalitet på $1 \%$ i uselekterte materialer $(11,12)$. Forbigående lette komplikasjoner er ikke uvanlig (10-22\%). Alvorlige komplikasjoner (oftest hypoksisk hjerneskade etter resuscitering) er imidlertid sjeldent, oftest under $1 \%$. Utfordringen fremover med tanke på mortalitet er at minst fem ganger så mange dør utenfor sykehus som i sykehus (1), og at langtidsmortaliteten etter utskrivning er svært høy, faktisk 10-15 ganger så stor som i en aldersjustert kontrollpopulasjon $(12,13)$.

\section{Samhandling mellom sykehus og Giftinformasjonen}

Som det fremgår av figur 2, kommer om lag $10 \%$ av henvendelsene til Giftinformasjonen fra sykehus. En typisk henvendelse vil være rett etter midnatt $i$ helgen, hvor en yngre person innbringes komatøs i akuttmottaket. Etter stabilisering og orienterende diagnostikk vil ofte vakthavende lege kontakte Giftinformasjonen, enten fordi man har sterk mistanke om forgiftning, eller fordi dette er en sentral differensialdiagnose hos komatøse yngre. Via vakthavende ved Giftinformasjonen får man informasjon om de ulike aktuelle agensene, og eventuelt henvisning til relevant informasjon på www. helsebiblioteket.no/forgiftninger. Innringer får også tilbud om kontakt med klinisk bakvakt. Mange håndterer deretter situasjonen selv, mens andre ønsker å diskutere med klinisk bakvakt som gir råd og holder kontakten med behandlende lege utover natten/neste dag, om dette skulle være nødvendig. Hvis ønskelig blir avidentifisert epikrise tilsendt Giftinformasjonen. På interne faglige møter diskuteres tilsendte epikriser som ledd i kvalitetssikring av tjenesten og i opplæring av eget personale.

\section{Nettbasert informasjon}

Vårt moderne samfunn preges av økende bruk av Internett som informasjonskanal. I tråd med dette har Giftinformasjonen utviklet et emnebibliotek om forgiftninger på det offentlige nettstedet helsebiblioteket.no (14). Her finnes retningslinjer for både den generelle og den spesielle forgiftningsbehandlingen. Totalt har vi utarbeidet 160 slike dokumenter, som blant annet omhandler planter, sopp, kjemikalier, gasser, terroragenser og ulike medikamenter. Her ligger også de norske antidotanbefalingene. Vanlig praksis på intensivavdelinger der man behandler forgiftede 


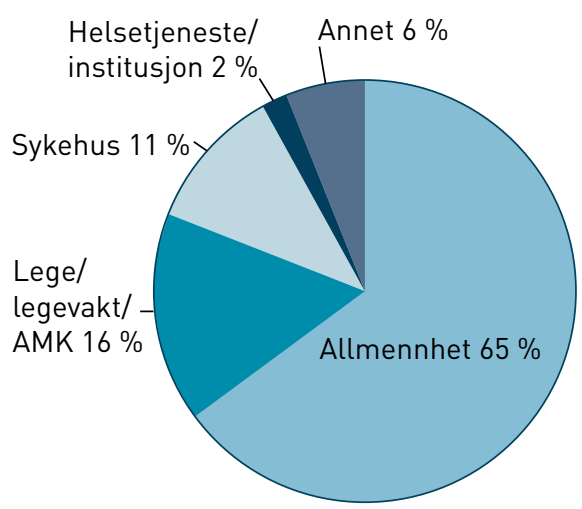

Figur 2 Oversikt over hvem som henvender seg til Giftinformasjonen. Tall fra Giftinformasjonens interne årsstatistikk for årene 2008, 2009 og 2010, og er et gjennomsnitt fra disse årene

pasienter, er å ta utskrift av aktuell informasjon og oppbevare denne i pasientpermen under oppholdet. Sykehuspersonell opplever at dette er en praktisk måte å innhente kunnskapsbaserte og oversiktlige behandlingsanbefalinger på. Den kontinuerlige oppdateringen av slike anbefalinger krever mye ressurser av Giftinformasjonen, men er nødvendig for å vedlikeholde kvaliteten på dokumentasjonen.

I tillegg har Giftinformasjonen en temaside om forgiftninger. Denne er beregnet for legfolk.og ligger ute på den nye helseportalen helsenorge.no.

\section{Giftinformasjonen - en gevinst?}

Giftinformasjonen er godt innarbeidet som en del av helsetjenesten. Det stilles krav om at virksomheten skal være kostnadseffektiv for samfunnet. Studier i både USA (15), Sverige (16) og Norge (17) synes å vise at slik drift er helseøkonomisk gunstig, ved at den forhindrer unødige henvisninger til lege, legevakt og sykehus, og gir en mer effektiv behandling i sykehus. I tillegg kommer den tryggheten som tjenesten gir befolkning og helsepersonell.

\section{Giftinformasjonen og fremtiden}

Erfaring tilsier at det er rasjonelt å samle spisskompetanse og dokumentasjon om giftige stoffer og forgiftninger på ett sted. Et tett samarbeid mellom en slik informasjonstjeneste og store kliniske referanseavdelinger er viktig. I et lite land som vårt er det sentralt å sikre at Giftinformasjonen har en eller flere slike avdelinger å spille på, hvor blant annet kliniske bakvakter kan rekrutteres fra.

Mens det ved utvikling av nye legemidler og kjemiske produkter etterstrebes lavere toksisisitet, er nå utfordringen desto større på grunn av økende fremstilling, distribusjon og (mis)bruk av nye narkotiske stoffer, illegale legemidler og natur(lege)midler med ukjente tilsetninger. Nye kommunikasjonskanaler og kjøp/salg via Internett gjør situasjonen uoversiktlig. Giftinformasjonen må fange opp nye trender og ny viten internasjonalt, og tilrettelegge dette for norske forhold. Virksomheten må også følge med på utviklingen av nye informasjonskanaler for å være tilgjengelig og synlig der det er bruk for tjenesten.

\section{Oppsummering}

Moderne forgiftningsbehandling er et samarbeid mellom kliniske enheter og Giftinformasjonen. En av den jubilerende organisasjonens viktigste oppgaver er å redusere antallet unødvendige henvendelser til legevakt og sykehus. Dette gjelder særlig ved eksponeringer hos barn, der foreldre etter kontakt med Giftinformasjonen ofte kan beroliges i hjemmet om at forgiftningsfaren er liten. En annen hovedoppgave er å gi oppdatert informasjon til helsepersonell via Internett eller rådgivningstelefonen om behandlingskrevende forgiftninger. Sist men ikke minst deltar Giftinformasjonen i kompetansebygging sammen med store kliniske avdelinger og relevante forskningsenheter. Dette arbeidet har vist seg å fungere meget godt, og bør videreutvikles de neste 50 år.

\section{Dag Jacobsen (f.1952)}

er spesialist i klinsk farmakologi, i indremedisin og i hjertesykdommer. Han er avdelingsleder ved Akuttmedisinsk avdeling, Oslo universitetssykehus Ullevål, og professor ved Universitetet i Oslo. Klinisk bakvakt ved Giftinformasjonen.

Ingen oppgitte interessekonflikter.

\section{Tarjei Rygnestad (f. 1954)}

er spesialist i anestesiologi og i klinisk farmakologi og professor. Klinisk bakvakt ved Giftinformasjonen.

Ingen oppgitte interessekonflikter.

\section{Berit Muan (f. 1960)}

er cand.pharm/dr.scient og avdelingsleder i Avdeling for farmakologi, Klinikk for diagnostikk og intervensjon, Oslo universitetssykehus. Hun var tidligere seksjonssjef ved Giftiformasjonen, Helsedirektoratet, og klinisk forskningsleder i farmasøytisk industri (Nycomed Imaging/Amersham/GE Healthcare). Ingen oppgitte interessekonflikter.

\section{Erik Andrew (f. 1945)}

er m.sci.pharm. og dr.philos. seniorrådgiver ved Giftinformasjonen. Har tidligere vært professor II i farmakologi/toksikologi ved Farmasøytisk institutt, Universitetet i Oslo, tidligere leder av Giftinformasjonen og klinisk forskningssjef (Vice President) i Nycomed Imaging. Ingen oppgitte interessekonflikter.

\section{Litteratur}

1. Lilleeng GH, Berg KJ, Gjertsen F et al. Akutte forgiftninger 1999-2004-sykelighet og dødelighet. Tidsskr Nor Lægeforen 2007; 127: $1023-7$.

2. Vo AST, Gjertsen F, Berg K et al. Mortalitet av forgiftninger - en toksikologisk undersøkelse. Norsk Farmaceutisk Tidsskrift 2008; 10: 24-9.

3. Rajka T, Heyerdahl F, Hovda KE et al. Acute child poisonings in Oslo: a 2-year prospective study. Acta Paediatr 2007: 96: 1355-9.

4. Wickstrøm E. Giftinformasjonssentralen (GIS). Om oppbyggingen av en ny helsetjeneste 1961-98. Cygnus - en norsk farmasihistorisk skriftserie. 2000; 5: 9-26.

5. Mattew H, Lawson AA. Acute barbiturate poisoning - a review of two years experience. Q J Med 1966; 35: 539-52.

6. Lyngar E. Akutte intoksikasjoner; betraktninger over et 10 ars materiale omfattende krigstiden. Tidsskr Nor Lægeforen 1954; 74: 351-4.

7. Clemmesen C. New line of treatment in barbiturate poisoning. Acta Med Scand 1954; 148: 83-9.

8. Hals PA, Jacobsen D. Resin haemoperfusion in levomepromazine poisoning: evaluation of effect on plasma drug and metabolite levels. Hum Toxicol 1984; 3: 497-503.

9. Pronczuk de Garbino J, Haines JA, Jacobsen D et al. Evaluation of antidotes: activities of the international programme on chemical safety. J Toxicol Clin Toxicol 1997; 35: 333-43.

10. Meredith TJ, Jacobsen D, Haines JA et al, red. Antidotes for poisoning by cyanide. Cambridge: Cambridge University Press, 1993.

11. Rygnestad T, Fagerhaug $\emptyset$. Akutte selvpåførte forgiftninger i Trondheims-området 1978-2002. Tids skr Nor Lægeforen 2004; 124: 2736 -9.

12. Heyerdahl F, Bjornas MA, Hovda KE et al. Acute poisonings treated in hospitals in Oslo: a one-year prospective study (II): clinical outcome. Clin Toxicol (Phila) 2008; 46: 42-9.

13. Bjørnaas MA, Jacobsen D, Haldorsen T et al. Mortality and causes of death after hospital-treated self-poisoning in Oslo: a 20-year follow-up. Clin Toxicol (Phila) 2009; 47: 116-23.

14. Emnebibliotek forgiftninger. www. helsebiblioteket.no/forgiftninger (2.9.2011).

15. Miller TR, Lestina DC. Costs of poisoning in the United States and savings from poison control centers: a benefit-cost analysis. Ann Emerg Med 1997; 29: 239-45

16. Anell A, Persson M. Giftinformationscentralens rådgivning - omtyckt och lönsam för samhället. Läkartidningen 2001; 98: 2926-30

17. Toverud EL, Pike E, Walløe L. The National Poison Center in Norway: user satisfaction and a health economic evaluation. Eur J Clin Pharmacol 2009; 65: $935-40$.

Manus mottatt 15.5. 2011, første revisjon innsendt 30.6. 2011, godkjent 17.8. 2011. Medisinsk redaktør Jon Amund Kyte. 